\title{
Medical futility, treatment withdrawal and the persistent vegetative state
}

\author{
Kenneth R Mitchell, Ian H Kerridge and Terence J Lovat University of Newcastle
}

\begin{abstract}
Authors' abstract
Why do we persist in the relentless pursuit of artificial nourishment and other treatments to maintain a permanently unconscious existence? In facing the future, if not the present world-wide reality of a huge number of persistent vegetative state (PVS) patients, will they be treated because of our ethical commitment to their humanity, or because of an ethical paralysis in the face of biotechnical progress? The PVS patient is cut off from the normal patterns of human connection and communication, with a life unlike other forms of human existence. Why the struggle to justify ending a life which, it is said, has suffered an irreversible loss of the content of consciousness? Elsewhere, the authors have addressed the ethical controversies and confusion engendered by ambiguous terminology, misuse of medical facts and the differing interpretations of what constitutes 'effective' treatment: in particular, the issue of whether in fact artificial nutrition and hydration is a medical treatment, or simply part of the obligatory care owed to all patients, permanently unconscious or not. In this paper, we intend to argue that recent analyses of medical futility, its meaning and ethical implications, despite an absence of public consensus, permit some tentative re-evaluation of our ethical obligations to the PVS patient.
\end{abstract}

The provision or otherwise of artificial nutrition and hydration (ANH) is, and has been for some years now, a matter of great controversy. The issue of ANH is made more complex when the patient is incompetent, that is to say, incapable of ever making a free and informed choice as to its provision or otherwise. The persistent vegetative state (PVS) patient is an example of such an incompetent patient for whom the resolution of this very complex issue has important life and death consequences.

\section{Key words}

Persistent vegetative state; medical futility; medical ethics; permanently unconscious; public policy; decision-making.

\section{The persistent vegetative state}

Surveys in Japan (1) and the Netherlands (2) indicate that 40 per cent of vegetative states are caused by severe head injuries which result in widespread severance of white-matter fibres to and from the cerebral cortex. A further 40 per cent are caused by hypoxic necrosis of the cerebral cortex following cardiac arrest or medical accident. Various acute cerebral diseases account for most of the remainder. The end-result is that patients in a persistent vegetative state are considered to have permanently lost the function of their cerebral cortex $(3,4)$.

The simplest way of understanding the difference between the cerebrally dead permanently unconscious PVS patient and brainstem death is to consider the roles played by the brainstem and the cerebral cortex as part of the central nervous system. The brainstem is the stemlike portion of the brain connecting the cerebral hemispheres with the spinal cord, which generates the capacity for consciousness and neocortical functioning, controlling autonomic capacity such as respiration and cardiovascular integrity, and integrating the physiological functioning of the person as a whole.

Additionally, it contains the activating or arousal system for the entire upper brain, called the ascending reticular activating system (ARAS). The cerebral hemispheres, or neocortex, in turn, are responsible for the content of consciousness. When brainstem death occurs, the capacity for neocortical functioning and thus consciousness, is lost. By contrast, the brainstem in the PVS condition, including the ARAS, is relatively intact, however, the cerebral hemispheres suffer irreversible damage (4). Thus, within a short period following the initial trauma, the patient will begin to breathe spontaneously, the eyes will open and 'wander' and respond normally to light, and periods of sleep will occur. The protective gag, cough and swallow reflexes are usually normal and hand-feeding is possible by placing food at the back of the throat, thus activating the involuntary swallow reflex. All voluntary reactions or behavioural responses reflecting consciousness, volition or emotion at the cerebral cortical level are absent. Noxious stimuli may activate peripherally located nerves, but there is no observable experience of pain 
or suffering. Only a brain with the capacity for consciousness can translate neural activity into an experience. The PVS patient may 'react' to painful stimuli, but he or she does not 'feel' pain in the sense of conscious discomfort of the kind that doctors would be obliged to treat and of the type that would or should seriously disturb the family (4). PVS patients, then, are awake but amented, that is, they manifest a complete loss of mental functions, they have lost the function of the cerebral cortex. They remain permanently unaware, and though about half die within 12 months, a quarter may survive for many years, even decades $(1,2)$. In a recent study of the prognosis of post-traumatic vegetative state patients (5), no patient who remained vegetative beyond three months became independent of nursing care. The continued survival of the PVS patient depends on basic nursing care and on an adequate supply of artificial nutrition and hydration.

However, the reliability of a diagnosis of PVS has a small degree of uncertainty because, as yet, no specific laboratory studies can confirm the clinical diagnosis of PVS. Although advances in neurological imaging (for example, Positron Emission Tomography PET) may assist in diagnosing neocortical damage, it remains unproven as to whether this will enable an accurate determination of neocortical death to be made (4). Furthermore, electroencephalography (EEG) is not helpful (6) and computed tomography and magnetic-resonance imaging only show evidence of severe brain damage, not that the cortex as a whole is non-functional. (In the absence of investigative measures to confirm diagnosis, the diagnosis of PVS depends upon sequential neurological observations made over a period of time (4). Although there is general agreement that there can be no immediate diagnosis of PVS, there is some dispute as to the point at which a confident diagnosis of PVS can be made. Many clinicians believe a diagnosis can be made after three months without patient improvement (6) whereas others, such as the AMA, set a conservative criterion for diagnosis as 12 months of unawareness (7).) Despite the element of uncertainty in the diagnostic process, extremely few patients who remain vegetative after three months ever recover cognitive functions where it is believed that the diagnostic criteria were correctly applied $(4,5)$. The few who do regain consciousness remain very severely physically and mentally disabled and dependent (5). (The chronological component of the diagnosis of PVS is of paramount importance as regards clinical management. In the early months, the goal is to stabilise the patient and provide a high standard of nursing care, adequate nutrition and access to stimulation programmes which may, in some cases, lead to clinical improvement (8). Once diagnosis of PVS has been made, the treatment goals may be entirely different.)

Extrapolations from surveys $(1,2,3,4,6,9)$ suggest that the number of new PVS patients increases by at least 2000 annually in the western world and by about 600 in the UK alone, with a prevalence of about 1500 for the UK (6) and 5000 for the USA (4). Such estimates are conservative and based on acute cases only. The number would dramatically increase with the addition of patients with chronic, dementing brain disorders who may eventually become vegetative.

\section{The cost of survival}

It is now 16 years since Karen Ann Quinlan (a PVS patient) occupied the collective ethico-legal minds of the western world. Yet, it is clear from accumulated writings that we are still concerned, if not puzzled about the ethical stance we should adopt towards such patients. There are, for example, concerns regarding their status and the definition and determination of death according to neocortical criteria $(4,10,11)$. Impetus for this has come from: 1$)$ the rapid advance in organ transplantation technology PVS patients would provide a potential source for scarce organs; 2) the need to ensure a just and fair allocation of scarce resources, and 3) regard for the autonomy and dignity of the PVS patient.

Concerns arising from the scarcity of medical resources have led some to propose that consideration of cost should be a factor in all clinical ethical decision-making, particularly in relation to patients such as those in persistent vegetative states. Should the cost of continued health care for the permanently unconscious, or for any patient, be a factor in clinical ethical decision-making? While costs vary, it is undeniable that it is a costly exercise to maintain these patients in a persistent vegetative state. It has been argued, for example, that an affluent society should feel obliged to meet the costs, whereas an impoverished community must first ensure a just allocation of its scarce health resources (12). It may also be argued that given the scarcity of medical resources in affluent societies, they also cannot afford the costs and must make clinical ethical decisions with due regard for cost-efficiency. Can the argument to meet the costs involved in maintaining a PVS patient be sustained in the face of the 5000 or so PVS patients in the USA alone, a figure that it has been predicted will increase significantly in the future, especially when coupled with the increased longevity of people? (4)

Because the PVS patient can survive for decades, when life-sustaining treatment, such as nutritional support is withdrawn, the cause of death may seem to be the act of withdrawal itself, not the significant impact of the condition itself. This problem is all the more vexing because the usual treatment issue in the case of a PVS patient is whether to stop artificial nutrition and hydration (ANH), still the most controversial form of treatment withdrawal. While it is widely accepted that nutritional support may be withdrawn when the burdens to the patient truly 
outweigh the benefits, PVS patients push our commitment to this patient-centred standard to the limit. It is said that the PVS patient experiences nothing (9): the benefits and burdens of continued treatment fall mainly on others.

\section{Futility and the obligation to feed}

Serious ethical consequences flow from the doctor's claim that a particular treatment is futile, and, although such claims have far-reaching implications, there is little consensus about how futility should be determined in practice (13). The debate on the meaning of futility and related operational criteria is still in its infancy (14), however, its history reaches back to medical antiquity (15), where the so-called quantitative and qualitative aspects of futility had already been clearly recognised $(16,17,18)$. Quantitative aspects of futility refer to a very high improbability or extreme unlikelihood of treatment success, an expression that is quasi-numeric; qualitative refers to the quality of the outcome that treatment would produce for the patient, for instance, treatment that fails to end total dependence on intensive medical care, as does nutritional support for the PVS patient, would be judged futile (19). The Hippocratic Corpus, for example, encouraged doctors to recognise the limits of medicine, 'to refuse to treat those who are overmastered by their diseases, realising in such cases medicine is powerless' (17). In modern terms, the perception of futility derived from the Hippocratic Corpus has been considered as probabilistic or quantitative (19). On the other hand, Plato had a qualitative perspective of futility which emphasised the inappropriateness of persisting with treatment which leaves the surviving patient with a useless life '... Medicine was not intended for them and they should not be treated even if they were richer than Midas' (18).

The qualitative aspect of futility highlights the need to weigh and compare the expected effects and the outcome benefits that might come from medical intervention. The provision of artificial nutrition and hydration for the PVS patient, like other medical treatments (for example the use of antibiotics), is subject to ethical reflection as to whether it is morally obligatory or morally optional. One of the more usual ways of determining whether a medical treatment is obligatory or optional is to consider its expected effects, benefits and burdens. For example, doctors may argue that artificial nutrition and hydration is effective in a limited sense, as alimentation or nutritional support intended to achieve carefully defined physiological objectives or goals. As a physiological intervention, alimentation is a medical treatment and can be effective in keeping PVS patients alive for years $(6,20)$. But what benefit does the PVS patient derive from continued existence? Nutritional support can effectively preserve multiple organ- systems in a PVS patient, but it cannot restore that patient to a conscious, reflective life: accepting of course, that it may support the unconscious patient until such time as he/she regains consciousness. Though generally of no great burden to the PVS patient, we may well ask whether such alimentary support is futile, especially since the patient remains totally dependent on medical care. It may be argued that it is futile because the ultimate goal of any medical intervention should be improvement of the patient's prognosis, comfort, well-being, or, general state of health $(19,21)$. Alimentation, though it produces certain positive and measurable physiological effects, does not, in the case of the PVS patient, ultimately result in either short or long-term benefits of the kind consistent with our humanity (6). Many of those who reach such a conclusion, nevertheless are reluctant to withdraw ANH from the PVS patient because: 1) the PVS patient is neither dead nor dying; 2) as the patient is generally robust, the act of withdrawing ANH seems like intentional killing; 3) the patient's family wish treatment to continue and, 4) the provision of $\mathrm{ANH}$ is regarded by them as morally obligatory (22). The reasons normally advanced for withdrawing treatment - incurable suffering, terminal illness and patient request for withdrawal of life-supporting treatment - do not apply in the case of PVS patients.

When then, if ever, does an obligation to feed the permanently unconscious cease? The view that artificial nutrition and hydration is a positive duty or obligation which remains in force always, but does not apply to every case, permits a re-evaluation of our ethical obligation to feed the unconscious when it is clinically certain their condition is irreversible (23). A positive duty, like ethical principles in general, has only prima facie standing, that is, though always valid, we are not necessarily obliged to carry out the duty in every case. The positive obligation to provide ANH to the permanently unconscious may be overriden, we believe, when we are morally certain that their condition is irreversible. Available clinical evidence would suggest that reasonable moral certainty exists somewhere between three months as a minimum (5) and twelve months for the 25 per cent or so who survive in the vegetative state for three years or more (24). Recourse to alimentation should therefore be conditional and done solely to maintain life until consciousness returns and not at all to maintain total medical dependence in a state of permanent unconsciousness which clinical data indicates is certain beyond twelve months posttrauma. When the clinical prognosis is certain, though not absolute, we believe there already exist sufficient moral reasons to make feeding the permanently unconscious optional. Such an action has adherents who base their decision either on futility grounds alone, or on the grounds that continued ANH is not cost-effective, or, on a combination of 
futility or costs with a negative net burden-benefit calculation, or simply on a profound sense that further treatment would be fundamentally wrong. People holding such views argue that even when patients are not irreversibly dying and their deaths are not imminent, medical treatment may be optional even if it could prolong life for an indefinite period (25).

The issue of whether the medically provided nutrition and hydration can become excessively burdensome to the patient and, therefore, constitute morally optional means, is not a major concern with the permanently unconscious. The medical reality, as we now know, is that the experience of pain and suffering is an attribute of consciousness. It is simply not possible, based on available evidence, for the permanently unconscious patient to experience the burdens of pain and suffering as these require the integrated functioning of both the brainstem and the cerebral cortex (9). The provision of ANH to these patients can never be perceived by them as a burden because they remain permanently unaware.

Even if we accept the conclusions of modern neurology regarding PVS patients and the absence of personal suffering, nonetheless, their condition is so alien that human compassion demands an end to the significant burdens and suffering (psychological, emotional, physical, financial) borne by both the family and the health care team and to a lesser extent, society $(23,26)$. To call continued life such as this a 'benefit', or, the absence of suffering as indicating a 'tolerable' burden, is, at the least, dubious. To argue that the 'benefit' is in our affirming their dignity and in maintaining human solidarity (12) is no more convincing than the counter-argument that we should affirm their dignity by allowing them to depart. But who should determine whether continued unconscious existence is a benefit? Feeding the PVS patient may be judged to be futile if the medically determined goal is to restore cognition, but it may nonetheless be regarded as worthwhile in terms of the emotional and symbolic benefits accruing to the patient's family or society.

We believe the view that continued ANH is a confirmation of the duty we have to keep faith with the PVS patient is unbalanced, because it both assumes that the patient would prefer a vegetative existence to death and ignores other values which call for compassionate action for the patient and the minimisation of suffering for those others involved with the patient. Unfortunately, mandating the use of ANH with PVS patients as public policy seems to have been adopted as a fundamental stand against involuntary euthanasia and the danger of the 'slippery slope' $(12,22)$. However, modern nourishment technology is now so advanced that not only must discretion be exercised in its initial use but also in its continued use in cases where it becomes clear that the hoped-for benefit is not achievable.

\section{Futility and who should decide?}

We recognise that the use of a determination that continued treatment is qualitatively futile, as a basis for overriding the positive obligation to provide nutrition to the irreversibly vegetative patient, is not without its problems (27).

While the debate on the meaning of futility is evolving, it is by no means an 'illusory' concept (28) and provides at least the beginning of a basis to limit or cease treatment without the need to debate, define and reach a socio-political consensus for what should be a fair procedure for allocating resources. Quite clearly though, there must occur a process through which a clear sense of public values will emerge on this matter.

In the meantime, we argue that the conclusion that $\mathrm{ANH}$ is qualitatively (and quantitatively) futile in the case of a surviving PVS patient is a clinical ethical decision involving a consideration of 1) the medical diagnosis of PVS; 2) the determination of a highly probable irreversibility, and 3) the wishes of the patient (if known), or the view of the patient's surrogate. Such shared decision-making is in contrast to those who argue that doctors are obliged to withhold futile therapies and that to offer them may constitute a form of negligence (29). The claim, then, that ANH is futile, in that it offers no reasonable hope of real benefit to the PVS patient, would represent a significant shift in the ethical obligations owed by the doctor to the patient. Once the clinical judgement has been made that unconsciousness is irreversible, ANH should be discontinued and the patient allowed to die. The doctors and care-givers, family and public, have all discharged their moral obligations by providing competent and loving care in their hope that the patient might recover consciousness (23).

The family may still elect to nourish the PVS patient at home, perhaps they believe it is their duty, or, they may simply wish the patient to die in the privacy of the family home. When the final diagnosis of irreversibility is made clinically certain, however, the hospital, it can be argued, has discharged its ethical obligation to the patient and should then cease the provision of artificial nutrition and hydration. However, the decision that certain medical goals are not worth pursuing, or, in the case of the PVS patient, not achievable, is value-laden and may come into conflict with other values involving the goals of therapy, the ends of medicine and those which for emotional, symbolic or religious reasons accord biological life alone as an outcome, the same status as cognitive and sapient life. In the case of the PVS patient, the determination of irreversibility can only be made by the doctors alone and given the problems of clinical diagnosis and prognosis, this determination is essentially a statement of probability which can only approach absolute certainty. Nevertheless, the determination of continued treatment as futile and thus optional, should be a shared 
judgement. In the short term this determination, this decision, should involve both the doctor and the patient's surrogate and there should be a sensitive discussion about futile therapies, withdrawal of treatment and what the surrogate would intend to achieve if treatment were continued. Decisions to withdraw therapy that is deemed futile for the PVS patient would then follow 1) clinical judgements regarding the irreversible nature of the condition and, 2) explicit considerations of the patient's surrogate's values and goals for therapy. (In essence, if used as a focus for discussion of prognosis, values, benefits, burdens, quality of life, and the ends and goals of medicine, rather than in the guise of an objective criterion for clinical decision-making, the concept of futility may enhance the process of shared decision-making in which the doctor and the patient's family, surrogate or others are involved $(30,31)$.) In the long term, social consensus must be sought on ways to resolve conflicts through a public process of social and political decision-making $(14,17)$. A decision to terminate treatment must be shared and may well be delayed until the family has had time to work through and accept the limited options available to them.

In Australia the legal position of decisions to terminate treatment remains unclear as it was until recently in the UK (6). In the USA, where there has been much more public and ethico-legal discussion, the concept of futility can sanction restrictions in the allocation of health care resources. Patients cannot demand 'futile' therapy, and society and doctors are under no obligation to provide such therapy (13). This, too, is largely the situation in Australia and the UK where the duty of care is not binding when treatment is judged 'futile'. Public policy leaves the determination of futility to reasonable medical judgement, and therein lies a large part of the problem. Although we might expect doctors to agree about the type of clinical evidence necessary to justify a futility claim, this is not the case in general. Doctors can, and do, disagree about two things with regard to medical futility - the probability of treatment success, and more pointedly, the goals of treatment. This latter problem is the one most pertinent to the PVS patient. Is the goal of sustaining a biological, but unconscious life in the case of PVS patients, sufficiently weighty to be assigned the status of a real and true benefit? The problem seems to be that some doctors fail to make the important distinction between the effect and its specific benefit and the overall outcome benefit of continued treatment to the patient and his/her life (19). Failure to make this distinction can elevate the importance of the physiologic effects of ANH over the benefit to the patient as a whole. It is no surprise, then, that the legal situation with respect to withdrawal of ANH from the PVS patient is unclear, and even less surprising that few doctors will withdraw ANH even when convinced that its continuation is funda- mentally wrong and not in the best interests of the patient. Such actions will only follow when it is clear that the medical profession as a whole is prepared publicly to acknowledge the futility of treating the PVS patient.

Perhaps it was for this reason that a working party of the Institute of Medical Ethics recently urged the medical profession to recognise publicly that withdrawal of artificial nutrition and hydration may be an appropriate way to manage vegetative patients (6). Public declarations of this kind have three important effects: first, they raise public awareness and generate discussion that leads on to a growing political consensus based on social conceptions of reasonableness, the fair distribution of scarce resources and the worthy goals and ends of medicine $(23,32)$; second, they enable doctors to raise the withdrawal option sensitively with the family of the PVS patient; finally, they help to clarify legally the duty of care owed by the doctor to the patient. It is in these three spheres that the issue of ANH and the PVS patient needs to be resolved. The exercise of care in the futility debate is essential as there are already efforts to extend the notion of futility beyond PVS to cases of severe dementia and organ failure.

Kenneth $R$ Mitchell, MSc, MED, PhD, Grad Dip RelSt, FAPsS, is Senior Lecturer in Health Law and Ethics in the Faculty of Medicine, University of Newcastle. Ian $H$ Kerridge, BA, BMed, (Hons), MPhil, is Clinical Lecturer in Health Law and Ethics in the Faculty of Medicine, University of Newcastle. Terence $\mathcal{f}$ Lovat, BEd, BLitt, MTheol, $M A, P h D$, is Senior Lecturer in Sociology and Ethics, the Faculty of Education, University of Newcastle.

\section{References}

(1) Higashi K, Sakato Y, Hatano M. Epidemiological studies on patients with a persistent vegetative state. fournal of neurology and neurosurgical psychiatry 1977; 40: 876-885.

(2) Minderhoud J M, Braakman R. Het vegeterende bestaan. Ned tijdschr geneeskd 1985; 129: 2385-2388.

(3) Jennett B, Plum F. Persistent vegetative state after brain damage. A syndrome in search of a name. Lancet 1972; 1: 734-737.

(4) Cranford R E. The persistent vegetative state: The medical reality. Hastings Center report special supplement 1988; 18(1): 33-37.

(5) Braakman R, Jennett B, Minderhoud J M. Prognosis of the post-traumatic vegetative state. Acta Neurochir (Wien) 1988; 95: 49-52.

(6) Institute of Medical Ethics Working Party on the Ethics of Prolonging Life and Assisting Death. Withdrawal of life-support from patients in a persistent vegetative state. Lancet 1991; 337: 96-98.

(7) Medical Ethics Committee of the BMA. Discussion paper on treatment of patients in persistent vegetative state. September, 1992

(8) Andrews K. Managing the persistent vegetative state. British medical joumal 1992; 305: 486-487. 
(9) AMA Council on Scientific Affairs. Persistent vegetative state and the decision to withdraw and withhold life support. Fournal of the American Medical Association 1990; 263: 426-430.

(10) Engelhardt Jr H R. Brain life, brain death, fetal parts. Fournal of medicine and philosophy 1989; 14:1-3.

(11) Gillett G. Consciousness, the brain and what matters. Bioethics 1990; 4: 181-198.

(12) Grisez G. Should nutrition and hydration be provided to permanently comatose and other mentally disabled persons? Linacre quarterly 1990; 57: 30-43.

(13) Lantos J D, Singer P A, Walker R M, et al. The illusion of futility in clinical practice. The American journal of medicine 1989; 87: 81-84.

(14) Callaghan D. Medical futility, medical necessity. The problem-without-a-name. Hastings Center report 1991; 22: $30-35$.

(15) Jecker N S. Knowing when to stop: the limits of medicine. Hastings Center report 1991; 22: 5-8.

(16) Johnson A R. The old ethics and the new medicine. Cambridge: Harvard University Press, 1990.

(17) Hippocratic Corpus, the art. In: Reiser S J, Dyck A J, Curran W J, eds. Ethics in medicine: historical perspectives and contemporary concerns. Cambridge, Massachusetts: MIT Press, 1977: 6-7.

(18) Plato. In: Grube G M, transl. Republic. Indianapolis: Hackett Publishing, 1981: 76-77.

(19) Schneiderman L J, Jecker N S, Jonsen A R. Medical futility: its meaning and ethical implications. Annals of internal medicine 1990; 112: 949-954.

(20) Miles S H. Nourishment and the ethics of lament. Linacre quarterly 1989; 56: 64-69.

(21) Boyle P, King L, O'Rourke K. The Brophy case: the use of artificial hydration and Nutrition. Linacre quarterly 1987; 54: 63-72.

(22) Diamond E V. Commentary on the AMA statement on tube feedings. Linacre quarterly 1987; 54: 73-76.

(23) Zimmerman A. Allowing the unconscious to depart. Linacre quarterly 1991 ; 58: 17-24.

(24) Jennett B, Dyer C. Persistent vegetative state and the right to die: The United States and Britain. British medical journal 1991; 302: 1256-1258.

(25) Beauchamp T L, Childress J F. Principles of biomedical ethics (3rd ed). New York: Oxford University Press, 1989.

(26) Schneiderman L J. Exile and PVS. Hastings Center report 1990; 21: 5 .

(27) Mitchell K R, Lovat T J. Permanently unconscious patients and the ethical controversies surrounding artificial nutrition and hydration: getting the facts straight. Linacre quarterly (in press).

(28) Truog R D, Brett A S, Frader J. The problem of futility. The New England journal of medicine 1992; 326: 1560-1564.

(29) Ramsey P. The patient as person: explorations in medical ethics. New Haven: Yale University Press, 1990: 3.

(30) Jecker N S, Pearlman R A. Medical futility: who decides? Archives of internal medicine 1992; 152: 1140-1144.

(31) Truog R D, Brett A S, Frader J E. 'Futility' as a criterion in limiting treatment: the authors reply to correspondence. The New England fournal of medicine 1992; 327: 1239-1241.

(32) Tomlinson T, Brody $H$. Futility and the ethics of resuscitation. Fournal of the American Medical Association 1990; 264: 1276-1280. 